\title{
Severe Dysplasia
}

National Cancer Institute

\section{Source}

National Cancer Institute. Severe Dysplasia. NCI Thesaurus. Code C8364.

A morphologic finding indicating the presence of severe cellular atypia associated with severe architectural changes in a tissue sample. 